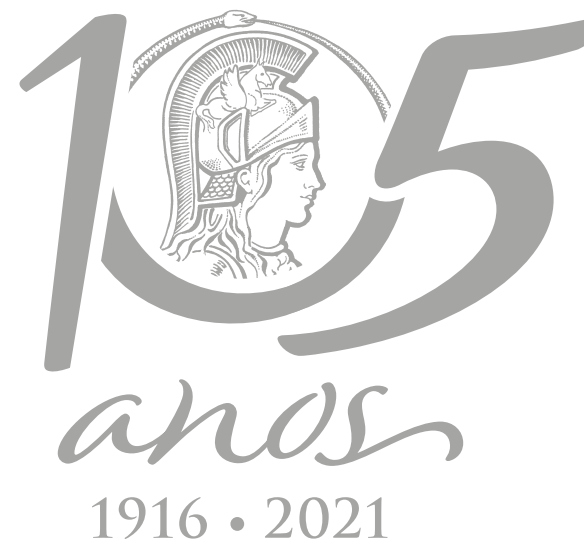

$1916 \cdot 2021$

\title{
ECOSYSTEMS
}

\section{Assessing the relationship between species traits and extinction risk at a regional level: an analysis involving Brazilian terrestrial mammals}

\author{
MATHEUS C. DRAGO, LETÍCIA M. RAPOSO \& DAVOR VRCIBRADIC
}

\begin{abstract}
One of the various concerns of conservation biology is determining why certain species are more threatened than others. In this study, we aim to relate the national conservation status of Brazilian mammals with the taxonomic group to which they belong and with three of their intrinsic traits: body mass, diet, and litter size. We compiled a database containing the species, their status, and their attributes, and a multiple correspondence analysis was applied to identify relationships between traits and status. The two groups that presented the highest relative frequencies of threatened species were "ungulates" and Carnivora. Additionally, mammals with body mass of $10 \mathrm{~kg}$ or more and with carnivorous diet had a higher relative frequency of threatened taxa. We found not only a strong relationship between intrinsic traits and conservation status, but also among the traits themselves, which highlights the role of the "group" variable as one of the best predictors of the risk that a given species be threatened. We believe our study has a broad potential for the conservation of species at the regional level, especially regarding the species currently classified as Data Deficient, and for identifying which species are prone to becoming threatened.
\end{abstract}

Key words: Biological attributes, Brazil, Mammalia, Red List, threatened species.

\section{INTRODUCTION}

Conservation biology is not only concerned with understanding the effects of human activities on other organisms, communities, and ecosystems, or with providing principles and tools for preserving biological diversity (Soulé 1985), but also with explaining why certain species present a higher risk of becoming threatened than others. Ecological knowledge helps to identify extinction-prone species, providing a basis for effective conservation actions (Angermeier 1995). However, in order to predict extinction risk, it is important to understand how multiple ecological factors interact with each other (Davidson et al., 2009) and which biological and ecological traits make a species more vulnerable (Chichorro et al. 2019). In this way, several studies provide evidence of a non-random pattern of species loss, both across ecological and geological time scales (e.g. McKinney 1997, Russell et al. 1998, Purvis et al. 2000, Cardillo 2003, Davidson et al. 2009, Verde Arregoitia 2016, Chichorro et al. 2019). Thus, besides external factors (e.g. habitat loss, hunting, overexploitation), there may be intrinsic traits that make some species more extinction-prone (Cardillo 2003). Consequently, species with certain life-history and ecological traits could be under a higher risk of becoming threatened (Davidson et al. 2009, 2012).

Purvis et al. (2000) highlighted three intrinsic traits related to extinction risk: high trophic level, slow life-history, and large body size. Species at higher trophic levels are more often at risk since 
they are more severely affected by disturbances on populations of other species across the food chain. Some related threats include, for example, prey depletion (Wolf \& Ripple 2016) and the fact that those species usually have large home ranges and low population densities (Carbone \& Gittleman 2002). On the other hand, species with slow life-histories would be more vulnerable to extinction threat because of their long gestations, low reproductive output, and delayed growth rates. Slower reproductive rates make it harder for populations to recover after disturbances (Pimm 1988). Body size, in turn, is one of the most well studied traits (Chichorro et al. 2019). Large body size is commonly related to or correlated with many characteristics that affect extinction-proneness (McKinney 1997), such as resource availability (Chichorro et al. 2019), slow life-histories and low population densities (Purvis et al. 2000). Large-bodied species may also be more likely to be targeted by hunters (Cardillo 2003).

Red Lists usually classify species into categories that represent their extinction risk, and the International Union for Conservation of Nature (IUCN) is responsible for one of the most famous assessments in this context: the IUCN Red List. IUCN bases its analysis on some criteria that, when interpreted together, allow assessing the probability of extinction of a given species. Among those criteria are, for example, population size and geographic range. Species are then classified in one of the following categories of threat: Least Concern (LC), Near Threatened (NT), Vulnerable (VU), Endangered (EN) and Critically Endangered (CR). Four other categories are also used when species are not classified in either of the aforementioned categories: Not Evaluated (NE), Data Deficient (DD), Extinct in the Wild (EW) and Extinct (EX).

Regional lists are also important when the intention is to identify which species are most vulnerable to extinction within a given geographic area (i.e. a country, a state, etc). In Brazil, a megadiverse country, the Instituto Chico Mendes de Conservação da Biodiversidade (ICMBio), an entity linked to the Brazilian Ministry of Environment, periodically publishes the socalled Red Books, identifying which species are considered nationally threatened and assessing their respective national conservation status. Even though ICMBio uses the same criteria and the same conservation status classification as the global list provided by IUCN, differences in the status of some species between the two lists may occur (Brito et al. 2010). Some factors responsible for divergences between the national and global lists reflect regional aspects related to the conservation of the species in Brazil and include the period in which the conservation statuses were assessed, variations in the evaluation process itself, and the fact that species threatened at the national level may not be threatened globally and vice versa (Drago \& Vrcibradic 2021).

Mammals represent one of the most threatened vertebrate groups, not only in terms of the number of imperiled species, but also in terms of population losses (Ceballos \& Ehrlich 2002). The Brazilian mammal fauna is one of the richest in the world, with over 700 species currently recorded from the country (Quintela et al. 2020). Habitat loss due to agricultural activity and mortality due to hunting/trapping are some of the main threats to Brazilian mammals, according to the Brazilian Red Book of Threatened Species of Fauna (ICMBIO/ MMA 2018). This pattern is also evident at a global scale as, according to the IUCN Red List website, agriculture/aquaculture and the use of biological resources are the two factors that most threaten mammal species worldwide. Additionally, according to the same website, mammals are also the group with the most 
species threatened by some types of threat considered in the database, including "human intrusions and disturbance" and "hunting/ trapping terrestrial animals". The variety of life-history and ecological traits found within mammals, particularly the terrestrial ones, is extensive, and there is a considerable amount of species-level data available in the literature. This makes this group suitable for analyses that relate the conservation status of species with their intrinsic traits. With a few exceptions (e.g. Lunney et al. 1997, McKenzie et al. 2007, Boyer 2008), most studies choose to address the global conservation status of the species, disregarding regional aspects and, consequently, regional threats (e.g. Purvis et al. 2000, Cardillo et al. 2005, 2008, Davidson et al. 2009). In this study, we aim to relate the national conservation status of Brazilian terrestrial mammal species with the taxonomic group to which they belong and with three of their intrinsic traits: average body mass, diet, and average litter size (as a lifehistory indicator). We intend to find out if the species' intrinsic traits influence their regional conservation status. We expect that, as it has been indicated in global analyses, species that are large-bodied, carnivorous and/or produce a low number of offspring will tend to be classified with a more worrying conservation status.

\section{MATERIALS AND METHODS}

\section{Database building}

We compiled a database containing all Brazilian mammal species and their conservation status according to the Brazilian Red Book of Threatened Fauna (ICMBio/MMA 2018). As our objective involves the conservation status of non-volant terrestrial species (including semi-aquatic ones), we did not include cetaceans, sirenians and chiropterans in our analyses. Pinnipeds, despite being part of the Order Carnivora, were also not included since most species in that group do not maintain resident populations in Brazil, and because of their association with the marine environment (even though they are semi-aquatic, as opposed to fully aquatic). We also did not include species classified as Not Evaluated (NE), Data Deficient (DD), Extinct (EX) or Not Applicable (NA; a category that regional lists use when species are not considered eligible for regional conservation status assessments). Data regarding the species' attributes were obtained mainly from online databases such as Myhrvold et al. (2015) and the IUCN Red List website, but some books and specialized guides (Reis et al. 2010, 2015, ICMBio/MMA 2018) were also used as sources. Because some primates and the Pampas deer (Ozotoceros bezoarticus) were evaluated by the ICMBio for their conservation status only at the subspecific level, we considered the status of the least threatened subspecies as the status of the species as a whole in those cases.

To better analyze our results and identify any relationships between the variables considered, we divided the species into seven groups: Cingulata, Carnivora, Didelphimorphia, Glires (comprising Rodentia and Lagomorpha), Pilosa, Primates, and "Ungulates" (comprising Artiodactyla and Perissodactyla). Data on average body mass, diet and average litter size were also divided into categories. The ranges considered for average body mass were: < 0.1 $\mathrm{kg}, 0.1$ to $<1 \mathrm{~kg}, 1$ to $<10 \mathrm{~kg}$, and $10 \mathrm{~kg}$ or more. The ranges for average litter size were: only one cub, $>1$ to two cubs, $>2$ to $<5$ cubs and five or more cubs. Regarding the diet of species, we categorized them according to whether the species is carnivorous, herbivorous, or omnivorous. Conservation status was considered as the response variable in this study and was categorized into two classes: species listed as Vulnerable (VU), Endangered (EN), and Critically Endangered (CR) were considered "threatened" 
and species listed as Least Concern (LC) and Near Threatened (NT) were considered "non-threatened".

\section{Statistical analyses}

For univariate analyses, the pairwise association between explanatory variables and the response variable was assessed by a Chi-square test or by Fisher's exact test, where appropriate. Cramer's V was calculated as a measurement of effect size.

The analysis of joint relationships between ecological traits and conservation status was conducted by multiple correspondence analysis (MCA). MCA is a multivariate descriptive technique used to explore categorical data and visualize relationships between variable categories by perceptual maps. Points located in the same direction of the origin and the same region of the space present more chances of being associated (Husson et al. 2011). This approach was chosen because it allows the analysis of all explanatory variables simultaneously with conservation status. All variables used in univariate analyses were used to construct the factorial axes of the MCA.

Also, as an exploratory approach, we applied the classification and regression tree (CART) algorithm (Breiman et al. 1984) to construct a model that graphically depicts relationships between predictor variables and conservation status. For the development of this model, the data were randomly divided into two parts: a training set, containing $70 \%$ of the data (256 species) and used in the construction of the tree, and a test set, with the remaining 30\% (108 species), used exclusively in the evaluation of the classification tree. The proportion of the conservation status classes was maintained in the subsets. Model performance was evaluated by accuracy (overall proportion of correctly classified species), sensitivity (percentage of threatened species correctly classified), specificity (percentage of non-threatened species correctly classified), and area under the receiver operating characteristic (ROC) curve (AUC). A 95\% confidence interval ( $\mathrm{Cl}$ ) using 2,000 stratified bootstrap replicates was calculated for each measure.

All statistical analyses were performed using the software $\mathrm{R}$ version 4.0.2 ( $\mathrm{R}$ Development Core Team 2020). The FactoMineR package (Lê et al. 2008) was employed to perform the MCA, the rpart package (Therneau et al. 2012) was used to build a classification tree model for conservation status of Brazilian mammals, and the pROC package (Robin et al. 2011) was used to calculate AUC and $95 \% \mathrm{Cl}$. P-value $<0.05$ was considered statistically significant.

\section{RESULTS}

Our database comprised 364 Brazilian mammal species for which we found reliable information on all aspects considered (i.e. average body mass, diet, and average litter size). Eighty-one species $(22.25 \%$ of the total) were considered threatened (i.e. classified as either Vulnerable, Endangered or Critically Endangered), whereas 268 (73.63\%) were classified as Least Concern and 15 (4.12\%) as Near Threatened (Figure 1a). The groups Glires, Primates and Didelphimorphia made up most of our database, with 167 (45.88\%), 108 (29.67\%) and 41 (11.26\%) species, respectively (Figure 1b). Additionally, 247 species (67.86\%) averaged less than $1 \mathrm{~kg}$ in body mass, highlighting the predominance of small species in the database (Figure 1c). Regarding diet, most of the species (230, or $63.19 \%$ ) were omnivorous (Figure 1d). Considering the average litter size, the two categories encompassing the highest number of species were "> 2 to < 5 cubs", with 140 species (38.46\%) and "only one cub", with 108 (29.67\%) (Figure 1e). 


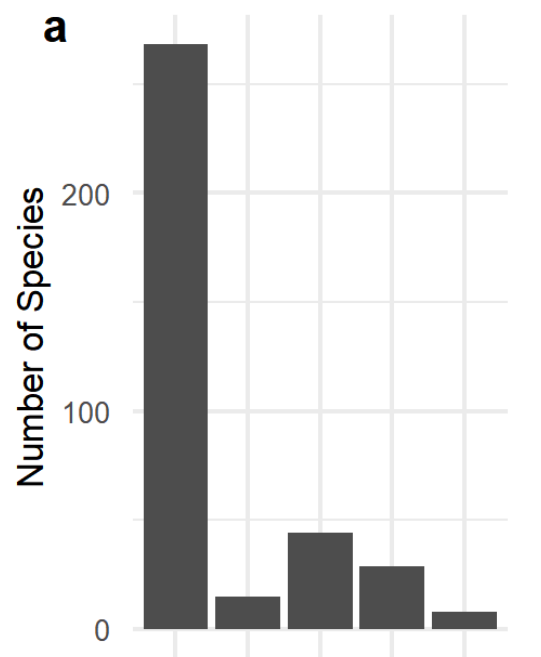

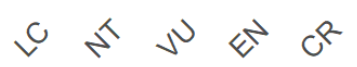

Conservation Status
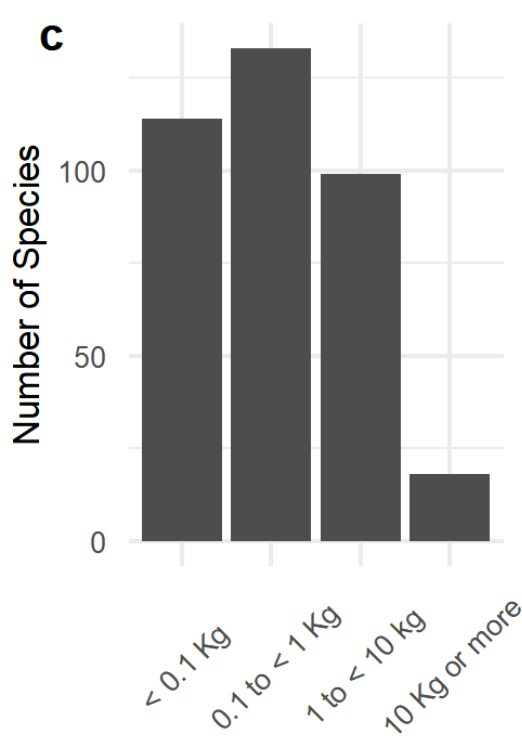

Average Body Mass (kg)
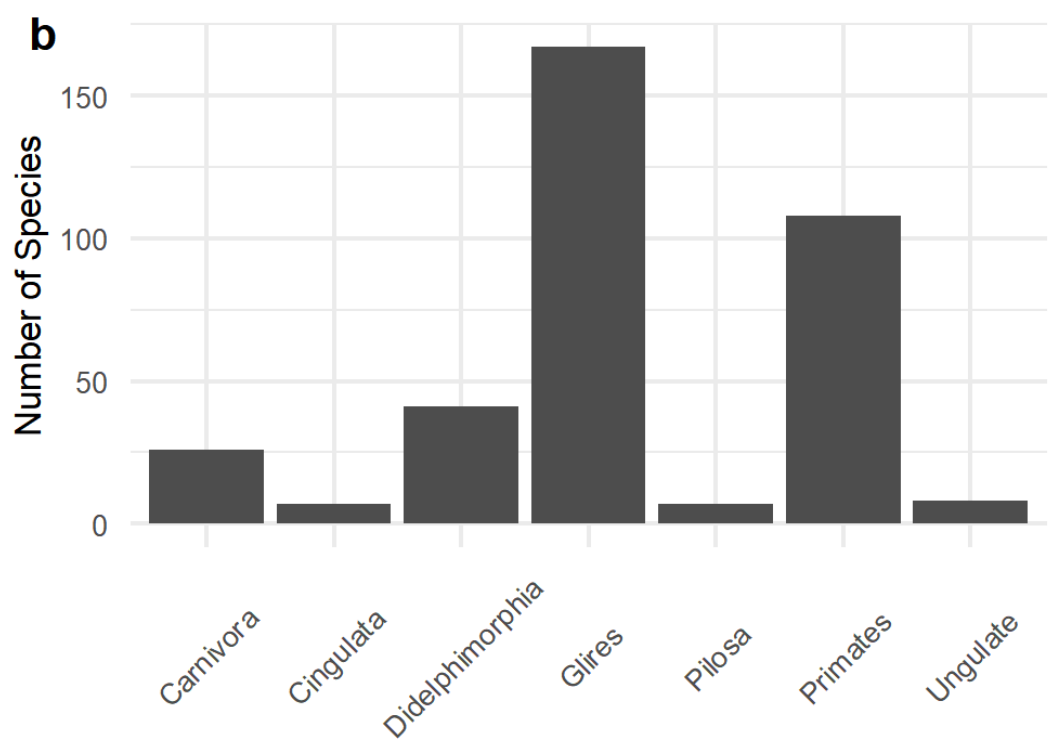

Group
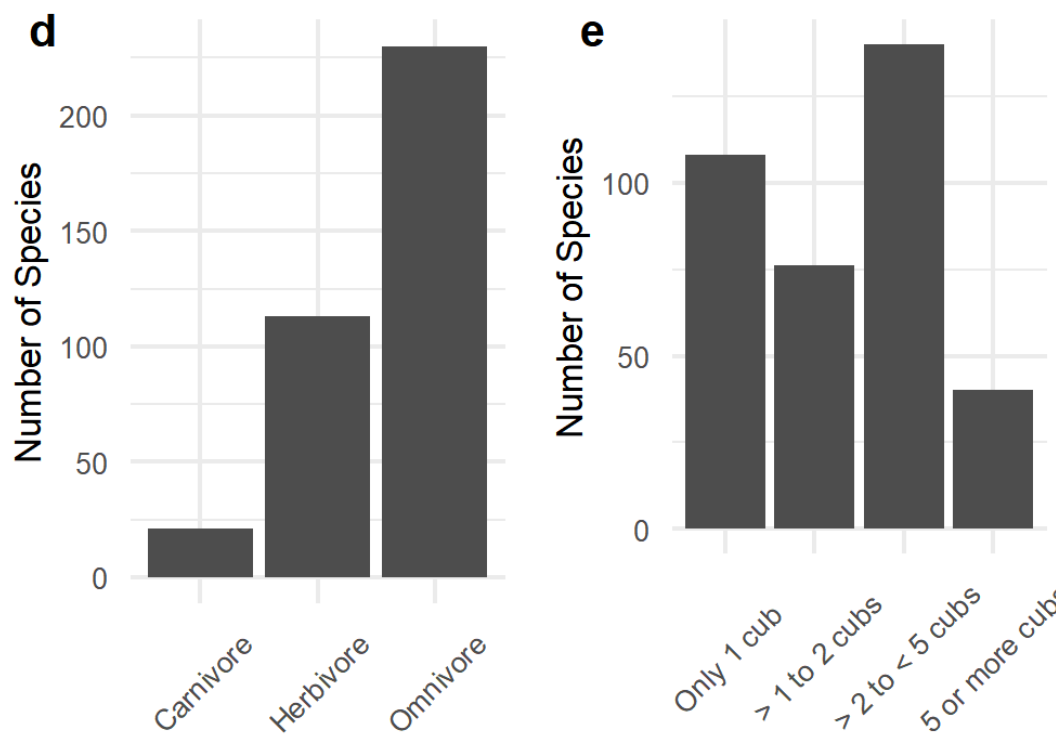

Diet

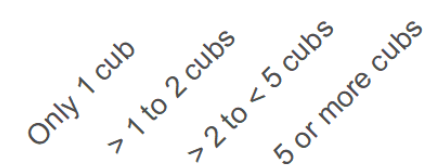

Average Litter Size (Cubs)

Figure 1. Number of Brazilian terrestrial mammal species according to: conservation status (a), taxonomic group (b), average body mass ( $\mathrm{kg})(\mathrm{c})$, diet (d), and average litter size (cubs) (e).

All pairwise associations among the categorical variables included in the study were statistically significant $(p<0.05)$. High associations (Cramer's $V>0.50$ ) were observed between group and diet (Cramer's $V=0.51$ ), group and average litter size (Cramer's V $=0.57$ ), and group and average body mass (Cramer's $V$ $=0.58)$.
The two groups that presented the highest relative frequencies of threatened species were Ungulates and Carnivora. In contrast, Glires and Didelphimorphia presented the highest proportions of non-threatened ones ( $p<$ 0.001) (Figure 2a). Average body mass was also statistically associated with conservation status $(p<0.001)$, with mammals weighing $10 \mathrm{~kg}$ or more 


\section{a}
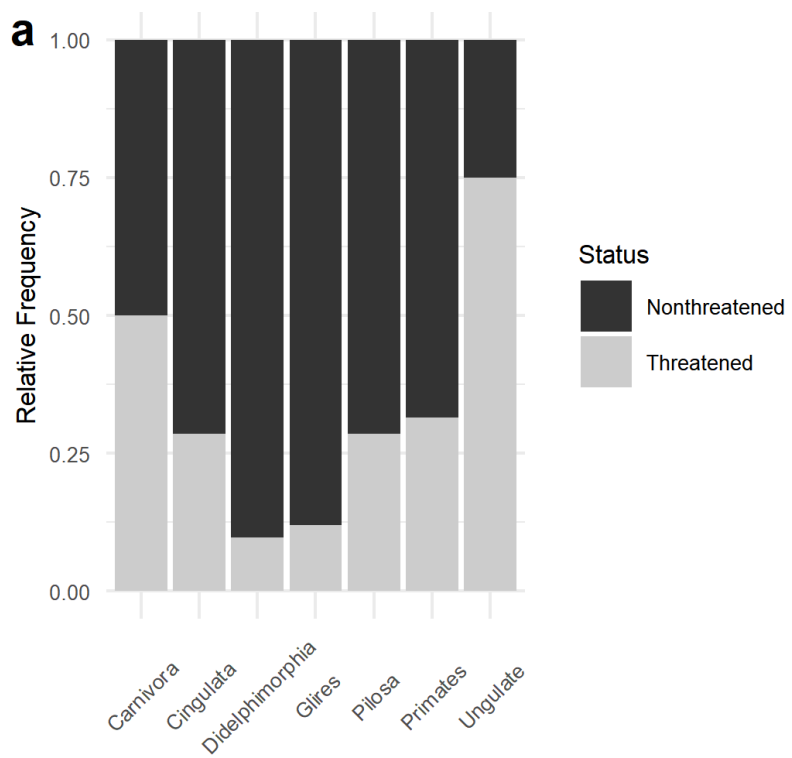

Group

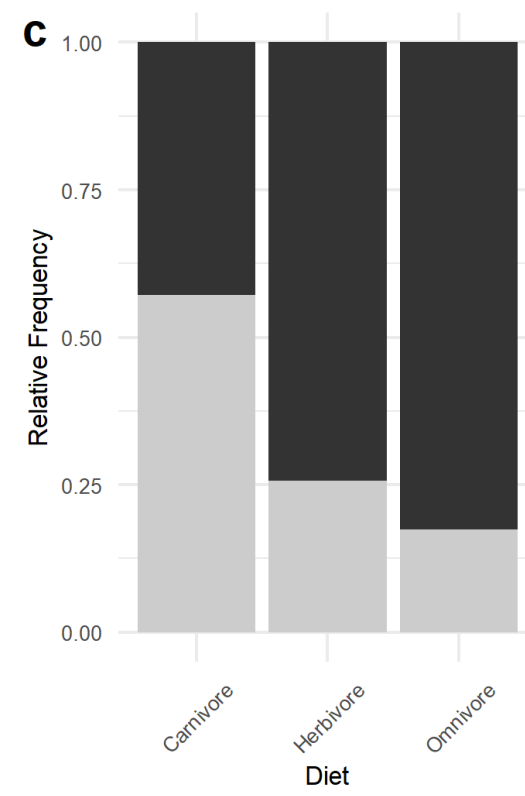

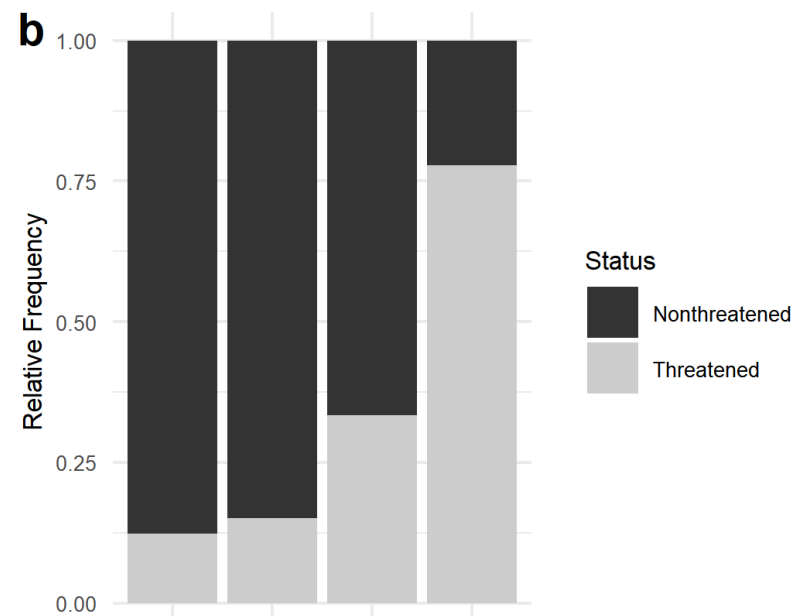

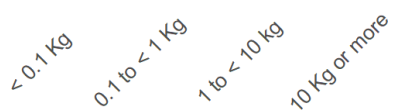

Average Body Mass $(\mathrm{kg})$
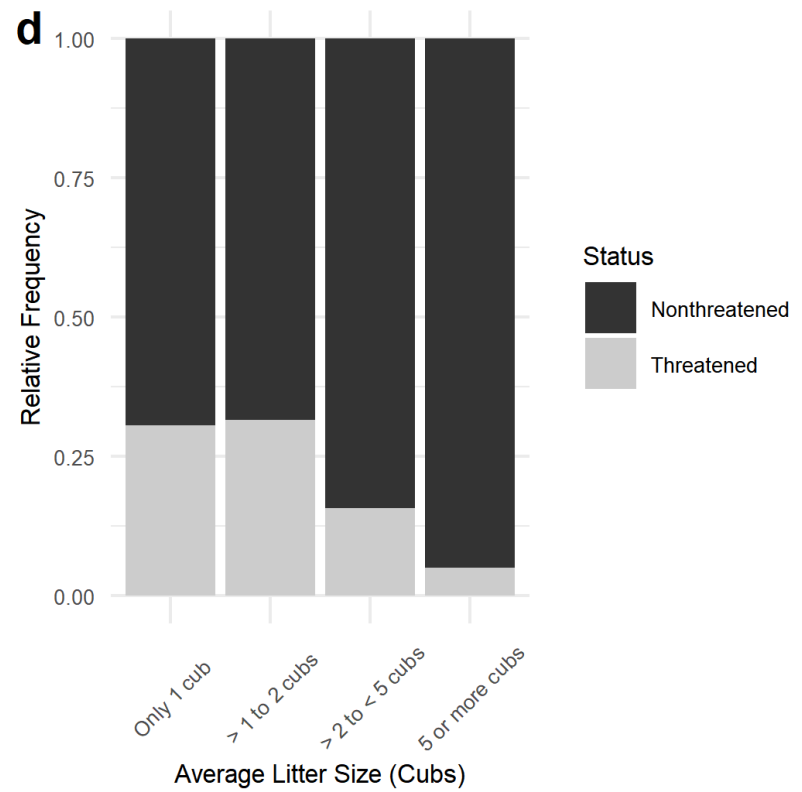

Figure 2. Relative frequency of threatened (in grey) and non-threatened (in black) mammals by: taxonomic group (a), adult body mass (kg) (b), diet (c), and average litter size (cubs) (d).

having a higher relative frequency of threatened taxa and mammals with body mass up to 10 $\mathrm{kg}$ having a higher relative frequency of nonthreatened taxa (Figure 2b). Diet and average litter size were also statistically associated with the outcome, with carnivorous mammals having a higher proportion of threatened species and omnivorous and herbivorous taxa having higher proportions of non-threatened species $(p<0.001)$ (Figure $2 c)$. The proportion of non-threatened species was higher than that of threatened ones in all litter size categories. However, this proportion became greater as the average number of cubs per litter increased ( $p<$ 0.001) (Figure 2d). 
The first two dimensions of the MCA explained $26.15 \%$ of the total variance, reaching $50 \%$ of the variability from the fifth dimension. Group and average body mass were the variables most correlated with dimension 1, and group and diet were the most correlated with dimension 2. The categories $<0.1 \mathrm{~kg}, \mathrm{VU}$, only 1 cub, $10 \mathrm{~kg}$ or more, and 1 to $<10 \mathrm{~kg}$ were the five most important to the first dimension, while the categories Primates, $10 \mathrm{~kg}$ or more, carnivore, > 2 to $<5$ cubs, and omnivore contributed the most to the second dimension.

Figure 3 shows the perceptual map of the categories included in the analysis. Regarding conservation status, LC was the only one on the left side of the map. Also on that side of the map were the groups Glires and Didelphimorphia, mammals up to $1 \mathrm{~kg}$ in body mass, with an omnivorous or herbivorous diet, and with more than two cubs. Threat categories EN, NT, $C R$, and VU were on the right side of the map. There was greater proximity between EN, NT, and CR categories, with a greater distance from VU status. The categories 0.1 to $<1 \mathrm{~kg}$ and omnivorous diet, near the LC category, were also positioned near the EN status. The group Primates was positioned close to NT and CR, while species with only one cub, or with adult body mass of 1 to $<10 \mathrm{~kg}$ were placed near CR. Carnivora and Pilosa and the carnivorous diet were positioned close to the VU status.

The classification tree (Supplementary Material-Figure S1), constructed to depict relationships between predictor variables and conservation status, used three out of the four variables included in the study: group, average body mass, and diet. Its accuracy was 0.83 (95\% Cl: 0.75-0.90) and, of the 84 non-threatened species in the test set, 81 were correctly classified (specificity $=0.96 ; 95 \% \mathrm{Cl}: 0.92-1.00$ ), indicating that the model has a low false positive rate (only three non-threatened species were classified as threatened). In contrast, sensitivity was relatively low, at 0.37 (95\% Cl: 0.21-0.58), with 15 of the 24 threatened species being classified as non-threatened, indicating a false negative rate equal to 0.63. The area under the ROC curve was 0.75 (95\% Cl: 0.64-0.87) and the decision rules were:

1) If the species weighs up to $10 \mathrm{~kg}$ and belongs to the groups Cingulata, Didelphimorphia, Glires or Pilosa, it was classified as non-threatened.

2) If the species weighs up to $10 \mathrm{~kg}$ and does not belong to the groups Cingulata, Didelphimorphia, Glires or Pilosa but has an omnivorous diet, it was classified as non-threatened.

3) If the species weighs up to $10 \mathrm{~kg}$, does not belong to the groups Cingulata, Didelphimorphia, Glires or Pilosa and does not have an omnivorous diet, it was classified as threatened.

4) If the species weighs $10 \mathrm{~kg}$ or more, it was classified as threatened.

\section{DISCUSSION}

Our analyses indicated that some intrinsic traits of Brazilian terrestrial mammal species are correlated with their degree of threat, concurring with several other studies that have attempted to relate biological and ecological traits of species with their proneness to being imperiled. Purvis et al. (2000), for example, showed that high trophic level, low population density, slow life-history and small geographic range are associated with high extinction risks in Primates and Carnivora. Those authors also emphasized the vulnerability of species with complex social structures, large home ranges and diurnal habits. Cardillo et al. (2005) concluded that the risk of extinction in larger mammal species 


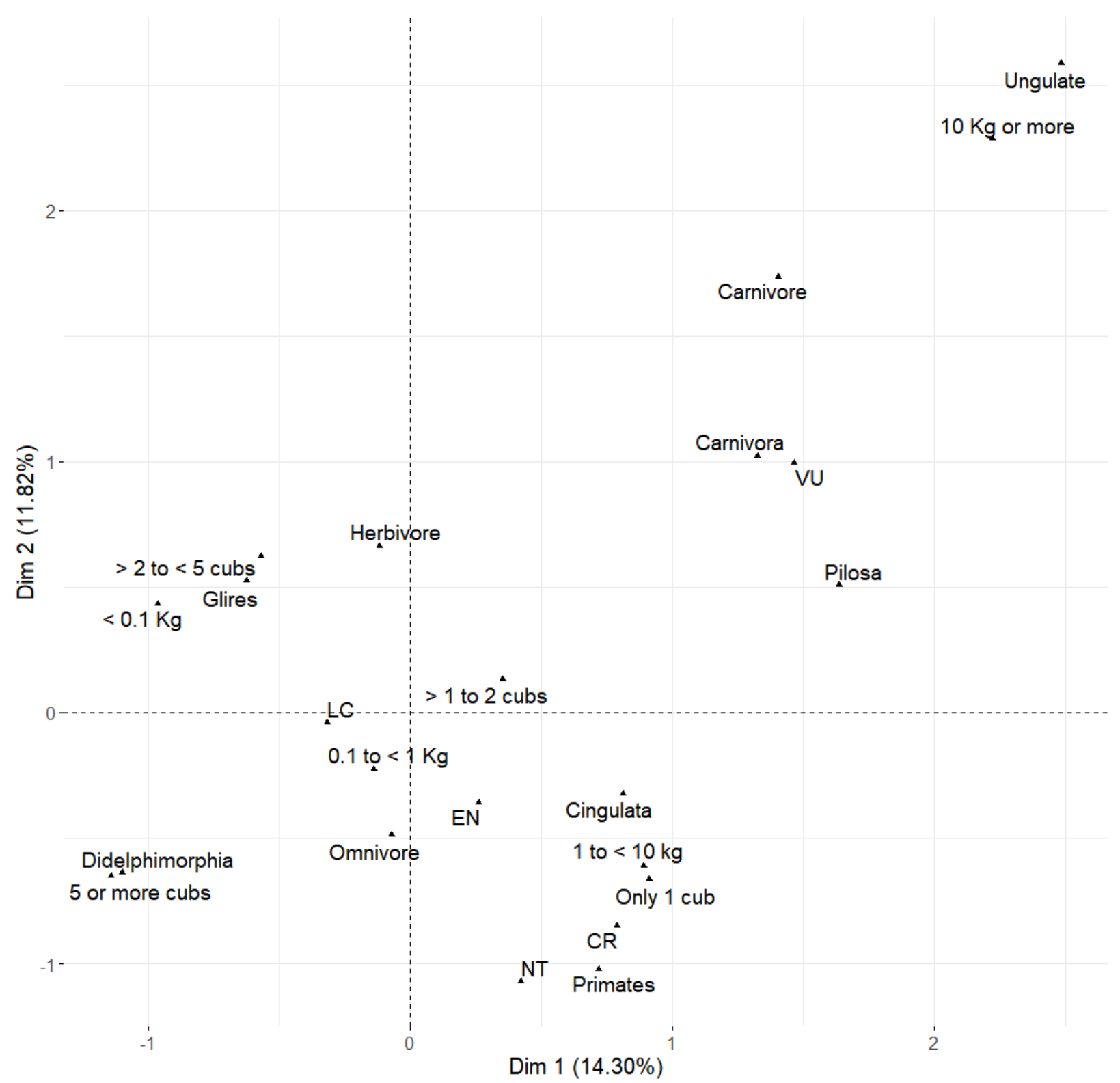

Figure 3. Multiple correspondence analysis map (projections on the first two dimensions) for the categories included in the analysis. LC: Least Concern, NT: Near Threatened, VU: Vulnerable, EN: Endangered, CR: Critically Endangered.

was driven by a combination of environmental factors and intrinsic traits. Later, Cardillo et al. (2008) analyzed nearly the whole of the class Mammalia and observed that the most significant predictors of extinction risk were geographical range extension, human population density and latitude. Davidson et al. (2009) also analyzed mammals worldwide and concluded that small geographic range, low population density, small group size, slow production rate, large home range, large body size, habitat mode and activity period are related to extinction risk.

Some of those traits have also been highlighted in other more generalized works as 
being associated with higher risks of extinction. Ehrenfeld (1970), for example, included specialized habitat preferences, intolerance of human presence, reproduction in aggregates and less adaptable behavioral patterns among the characteristics that increase the risk of extinction of a species. Terborgh (1974), in his turn, mentioned poor dispersal ability and migratory habits, whereas McKinley (1997) highlighted specialization and some abundance traits like localized geographic range and low population density as important characteristics to be considered.

The problem with many of these variables is the lack of data on them for many of the considered species, which is noticeable regarding the smaller-bodied ones. Rodents, for example, make up almost half of the taxa in our list and the information on biological traits is scarce for several species in the group. However, it is also important to consider three other important points. First, as in other studies, we chose to use the average body mass of the species as a measure of body size. Although this is the parameter usually employed, GonzálezSuárez et al. (2013) noted that distinct threats can increase the risk of species of different body size ranges. Thus, while small-sized habitat specialists tend to be more threatened by habitat-modifying processes, larger species with small litters tend to be more threatened by actions that directly affect individual survival, like hunting and fishing. Predicting extinction risk thus requires considering both the threat type and using related variables in comparative analysis (Murray et al. 2014). Davidson et al. (2009) pointed out that it may be more important to consider the body size of a species relative to other species that share similar ecological traits. Those authors observed, as we did, that there are threatened species in all body mass ranges. Consequently, the influence of body mass should be interpreted from a comparative and not an absolute point of view. An interesting fact worth mentioning is that while large mammals are more likely to become threatened (as observed in our study), most species in our database categorized as Critically Endangered (CR) were small-bodied (< $10 \mathrm{~kg}$ ).

Second, we have divided the diet of species into what we believe to be the simplest possible classification: carnivore, herbivore, and omnivore. Although we recognize that each of those could be divided into several subcategories, we believe that, by choosing the simplest option, the classification of the species becomes more appropriate since each species becomes associated with only one type of diet (i.e. if we had divided each category, the classification of generalist species that feed on a variety of items would be impaired).

Thirdly, unlike other studies, we chose not to include geographic range or abundance as parameters in our analysis as these attributes are already considered in conservation status assessments, at least indirectly (ICMBio/MMA 2018). We recognize, however, that several studies have tested the relationship between both range size and population density and these two attributes were considered relevant for mammals (e.g. Purvis et al. 2000, Cardillo et al. 2008, Davidson et al. 2009, Verde Arregoitia 2016, Chichorro et al. 2019).

In this context, two recently published papers deserve to be highlighted for having reviewed the relationship between species traits and extinction risk. Verde Arregoitia (2016) reviewed 68 studies of mammalian extinction risk and observed that, while Primates and Carnivora were the subject of more dedicated studies, there was a lack of research effort on small mammals. Chichorro et al. (2019), in their turn, although not focusing exclusively on mammals, tried to identify taxonomic and 
spatial biases and robust predictors of extinction risk. Those authors noted that only geographical range and location (the study's geographical setting) were significant in at least half of the 173 analyzed studies. Also, even though body size did not present a consistent response in general, they observed a tendency for its effect to be positively correlated to the extinction risk in mammals, which concurs with the results of our study.

We not only found a strong relationship between intrinsic traits of species and conservation status, but also among the traits themselves. As many species traits result from shared evolutionary history (Davidson et al. 2009), this was already expected. Species that belong to the same taxonomic group tend to present similar traits and, considering that high associations were observed between mammal group and all traits and that some groups presented many more threatened species than others (both in absolute and relative terms), the group to which a species belongs may be, in this way, one of the best predictors of the possibility of that species being threatened or not.

Although our classification tree reached a similar accuracy, sensitivity and specificity to those of other much more complex studies (e.g. Davidson et al. 2009), it may not be suitable for official conservation status assessments and should be interpreted only as an exploratory approach. We believe the high false-negative rate was due to the model being based on few variables (all of them qualitative), to the fact that most taxa were listed as Least Concern and, as suggested by Davidson et al. (2009), to the possibility of the extinction risk of those species being associated to factors other than the ones included in the model.

We believe the present study has a broad potential for the conservation of species at the regional level. Applying the knowledge generated here could be potentially useful for the conservation of species classified as Data Deficient, for example (see Bland et al. 2015). Although we recommend caution when making certain assumptions and admit that any type of generalization requires serious considerations, our results suggest that Data Deficient species that present some traits such as a carnivorous diet, a low number of offspring per litter, and large body size would have greater chances of being threatened nationally compared to species that present the opposite traits. Considering factors such as rarity, it is important to consider, however, that many of the species currently classified as Data Deficient may already be threatened regardless of their traits. Another potential use of the results of our work that we highlight here is that of identifying which species are more prone to become threatened soon. The ocelot, Leopardus pardalis, could be considered an example: the species is carnivorous, weighs more than $10 \mathrm{~kg}$ and, even though it is classified as Least Concern nationally (ICMBio/MMA 2018), its global population is considered as "decreasing" according to the IUCN Red List. Some ungulates could also be considered as examples, given their large body size and low reproductive output.

Although we used data available in the literature to build our database, we recognize that fieldwork is essential for population monitoring and to keep databases up to date. As observed by Cardillo \& Meijaard (2012), comparative studies like this one rarely influence conservation practices because of their proactive approach (policies, in contrast, usually have a reactive approach) and of their results, which are often ambiguous and difficult to translate into policies. Those authors thus encourage the adoption of a smaller picture view (i.e. to restrict the scope of comparative analysis). We hope that, by choosing to focus on 
Brazilian terrestrial mammals (thus restricting both the geographical and taxonomic scope), we have been able to achieve clearer and more useful results for conservation policies.

\section{Acknowledgments}

We would like to thank F. H. G. Rodrigues, M. L. Lorini and R. H. T. Oliveira for giving suggestions that contributed to the development and improvement of this work, and Coordenação de Aperfeiçoamento de Pessoal de Nivel Superior (CAPES) for the master's scholarship granted to $M C D$.

\section{REFERENCES}

ANGERMEIER PL. 1995. Ecological attributes of extinctionprone species: loss of freshwater fishes of Virginia. Conserv Biol 9: 143-158.

BLAND LM, COLLEN B, ORME CDL \& BIELBY J. 2015. Predicting the conservation status of data-deficient species. Conserv Biol 29: 250-259.

BOYER AG. 2008. Extinction patterns in the avifauna of the Hawaiian islands. Divers Distrib 14: 509-517.

BREIMAN L, FRIEDMAN J, STONE CJ \& OLSHEN RA. 1984. Classification and regression trees, $1^{\text {st }}$ ed, Boca Raton: Chapman \& Hall/CRC, 368 p.

BRITO D ET AL. 2010. How similar are national red lists and the IUCN Red List? Biol Conserv 143: 1154-1158.

CARBONE C \& GITTLEMAN JL. 2002. A common rule for the scaling of carnivore density. Science 295: 2273-2276.

CARDILLO M. 2003. Biological determinants of extinction risk: why are smaller species less vulnerable? Anim Conserv 6: 63-69.

CARDILLO M, MACE GM, GITTLEMAN JL, JONES KE, BIELBY J \& PURVIS A. 2008. The predictability of extinction: biological and external correlates of decline in mammals. Proc $R$ Soc B 275: 1441-1448.

CARDILLO M, MACE GM, JONES KE, BIELBY J, BINIDA-EMONDS ORP, SECHREST W, ORME CDL \& PURVIS A. 2005. Multiple causes of high extinction risk in large mammal species. Science 309: 1239-1241.

CARDILLO M \& MEIJAARD E. 2012. Are comparative studies of extinction risk useful for conservation? Trends Ecol Evol 27: 167-171.

CEBALLOS G \& EHRLICH PR. 2002. Mammal population losses and the extinction crisis. Science 296: 904-907.
CHICHORRO F, JUSLÉN A \& CARDOSO P. 2019. A review between species traits and extinction risk. Biol Conserv 237: 220-229.

DAVIDSON AD, BOYER AG, KIM H, POMPA-MANSILLA S, HAMILTON MJ, COSTA DP, CEBALLOS G \& BROWN JH. 2012. Drivers and hotspots of extinction risk in marine mammals. Proc Natl Acad Sci USA 109: 3395-3400.

DAVIDSON AD, HAMILTON MJ, BOYER AG, BROWN JH \& CEBALLOS G. 2009. Multiple ecological pathways to extinction in mammals. Proc Natl Acad Sci USA 106: 10702-10705.

DRAGO MC \& VRCIBRADIC D. 2021. The importance of addressing different Red Lists in conservation studies: an analysis comparing the conservation status of Brazilian mammals. Anim Biodiv Conserv 44: 79-88.

EHRENFELD DW. 1970. Biological Conservation, New York: Holt, Rinehart and Winston of Canada, $176 \mathrm{p}$.

GONZÁLEZ-SUÁREZ M, GÓMEZ A \& REVILLA E. 2013. Which intrinsic traits predict vulnerability to extinction depends on the actual threatening processes. Ecosphere 4: 1-16.

HUSSON F, LÊ S \& PAGĖS J. 2011. Exploratory multivariate analysis by example using R, Boca Raton: CRC press, 235 p.

ICMBIO/MMA. 2018. Livro Vermelho de Fauna Brasileira Ameaçada de Extinção, Volume II, Mamíferos, Brasília: Instituto Chico Mendes de Biodiversidade, 622 p.

LÊ S, JOSSE J \& HUSSON F. 2008. FactoMineR: an R package for multivariate analysis. J Stat Softw 25: 1-18.

LUNNEY D, CURTIN AL, FISHER D, AYERS D \& DICKMAN CR. 1997. Ecological attributes of the threatened fauna of New South Wales. Pac Conserv Biol 3: 13-26.

MCKENZIE NL ET AL. 2007. Analysis of factors implicated in the recent decline of Australia's mammal fauna. J Biogeogr 34: 597-611.

MCKINNEY ML. 1997. Extinction vulnerability and selectivity: combining ecological and paleontological views. Annu Rev Ecol Syst 28: 495-516.

MURRAY KA, VERDE ARREGOITIA LD, DAVIDSON A, DI MARCO M \& DI FIONZO MMI. 2014. Threat to the point: improving the value of comparative extinction risk analysis for conservation action. Glob Change Biol 20: 483-494.

MYHRVOLD NP, BALDRIDGE E, CHAN B, SIVAM D, FREEMAN DL \& MORGAN ERNEST SL. 2015. An amniote life-history database to perform comparative analyses with birds, mammals, and reptiles. Ecology 96: 3109.

PIMM SL, JONES SL \& DIAMOND J. 1988. On the risk of extinction. Am Nat 132: 757-785. 
PURVIS A, GITTLEMAN JL, COWLISHAW G \& MACE GM. 2000. Predicting extinction risk in declining species. Proc $\mathrm{R}$ Soc B 267: 1947-1952.

QUINTELA FM, ROSA CA \& FEIJÓ A. 2020. Updated and annotated checklist of recent mammals from Brazil. An Acad Bras Cienc 92: e20191004.

REIS NR, PERACCHI AL, BATISTA CB \& ROSA GLM. 2015. Primatas do Brasil: guia de campo, Rio de Janeiro: Technical Books, 328 p.

REIS NR, PERACCHI AL, FREGONEZI MN \& ROSSANEIS BK. 2010. Mamíferos do Brasil: Guia de Identificação, Rio de Janeiro: Technical Books, 557 p.

ROBIN X, TURCK N, HAINARD A, TIBERTI N, LISACEK F, SANCHEZ JC \& MÜLLER M. 2011. pROC: an open-source package for $\mathrm{R}$ and $\mathrm{S}+$ to analyze and compare ROC curves. BMC Bioinformatics 12: 1-8.

RUSSELL GJ, BROOKS TM, MCKINNEY MM \& ANDERSON CG. 1998. Present and future taxonomic selectivity in bird and mammal extinctions. Conserv Biol 12: 1365-1376.

SOULÉ M. 1985. What is conservation biology? BioScience 35: $727-734$.

TERBORGH J. 1974. Preservation of natural diversity: The problem of extinction prone species. Bioscience 24 : 715-722.

THERNEAU TM, ATKINSON B \& RIPLEY MB. 2012. Rpart: recursive partitioning and regression trees. $R$ package version 4.0-2. Available at <http://CRAN.R-project.org/ package=rpart>.

VERDE ARREGOITIA LD. 2016. Biases, gaps, and opportunities in mammalian extinction risk research. Mammal Rev 46: 17-29.

WOLF C \& RIPPLE WJ. 2016. Prey depletion as a threat to world's large carnivores. Roy Soc Open Sci 3: 160252.

\section{SUPPLEMENTARY MATERIAL}

Figure S1

\section{How to cite}

DRAGO MC, RAPOSO LM \& VRCIBRADIC D. 2021. Assessing the relationship between species traits and extinction risk at a regional level: an analysis involving Brazilian terrestrial mammals. An Acad Bras Cienc 93: e20210761. DOI 10.1590/0001-3765202120210761.

Manuscript received on May 20, 2021;

accepted for publication on August 24, 2021

\section{MATHEUS C. DRAGO 1}

https://orcid.org/00000-0003-3737-8552

\section{LETÍCIA M. RAPOSO ${ }^{2}$}

https://orcid.org/00000-0003-0613-5582

\section{DAVOR VRCIBRADIC ${ }^{3}$}

https://orcid.org/00000-0002-6355-3441

${ }^{1}$ Programa de Pós-Graduação em Ciências Biológicas (Biodiversidade Neotropical), Universidade Federal do Estado do Rio de Janeiro, Avenida Pasteur, 458, 22290-250 Rio de Janeiro, RJ, Brazil

${ }^{2}$ Universidade Federal do Estado do Rio de Janeiro, Departamento de Métodos Quantitativos, Avenida Pasteur, 458, 22290-250 Rio de Janeiro, RJ, Brazil

${ }^{3}$ Universidade Federal do Estado do Rio de Janeiro, Departamento de Zoologia, Avenida Pasteur, 458, 22290-250 Rio de Janeiro, RJ, Brazil

Correspondence to: Matheus C. Drago

E-mail:matheusdrago96@gmail.com

\section{Author contributions}

MCD wrote the manuscript and was responsible for the database building, LMR performed the statical analysis, and DV supervised all stages of the preparation of the manuscript. LMR and DV also contributed to the writing.

\section{(cc) BY}

